\title{
2006-121: MINDING THE GAP: AN INTRODUCTORY COURSE ON ENGINEERING AND PUBLIC POLICY
}

\section{Robert Green, Mississippi State University}

Robert A. Green is the Undergraduate Coordinator for the James Worth Bagley College of Engineering at Mississippi State University. He has a BS degree in Chemical Engineering, an MS degree in Mechanical Engineering, and an MA in National Security and Strategic Studies from the US Naval War College. He is also pursuing a Ph.D. in Public Policy and Administration at Mississippi State. He is a registered professional engineer and was a research engineer for 14 years prior to assuming his current position.

\section{Jerry Emison, Mississippi State University}

Jerry Emison is an Associate Professor of Political Science and Public Administration at Mississippi State University. His research interests concern the effectiveness of public environmental institutions, professionalism in city planning and engineering, and environmental consequences of growth management. He is a registered professional engineer, a board-certified diplomate of the American Academy of Environmental Engineers and a member of the American Institute of Certified Planners. 


\title{
Minding the Gap: An Introductory Course on Engineering and Public Policy
}

\begin{abstract}
There exists a gap between engineering and public policy which must be bridged. Engineers are affected by public policy but are seldom involved in setting policy. Engineers, and the decisions they make, also affect public policy. Those who set the policy frequently do not have a full appreciation of the technological issues involved and the engineers often do not appreciate the implication of their decisions on society. If engineers do not take a more active role in the setting of public policy, they will be left to work within the policies set by others who may lack adequate technical skills and they will be remiss in their duties as citizens to foster good policy. If the policy setters do not develop a greater appreciation of the technological issues involved they will develop and implement policies that are less than optimal. A course has been developed and offered that brings engineering and political science students together to explore public policy issues. As a result of the class, the students have a greater appreciation of the other field of study and they are better equipped to develop and implement policy.
\end{abstract}

\section{Introduction}

Public policy and engineering issues are becoming more intertwined as problems facing society become ever more complicated. A long-held tenet of engineering is that the practice of engineering should be of benefit to society as a whole, but many engineering works have both positive and negative consequences to society. This then requires that the engineering problems be addressed in the public policy arena as well as the technical engineering arena. The reality is, however, that most engineers are not adequately prepared to view problems from the perspective of public policy and most public policy makers are not adequately prepared to address problems from the technical perspective. Further, engineers often do not look for the larger public policy implications that may result from their decisions.

Issues such as nanotechnology, biotechnology, energy, the environment, and telecommunications are important to society but carry risks to the public as well. These risks are not always technical in nature, but are increasingly becoming more of a public policy issue. A few years ago, when energy prices in California were skyrocketing, the engineers stepped forward with a solution that involved placing small power generating plants in neighborhoods to provide supplemental power during peak electricity usage. The plants were to be fueled by natural gas, have a small footprint, and be relatively inexpensive to build and operate. What was seemingly a good technological solution became a public policy problem as citizens said they did not want the plants in their neighborhoods.

The problem does not rest solely with engineers however. Those involved in setting public policy are typically educated in social sciences or liberal arts and may eventually earn degrees in law. 
Just as engineering may not adequately prepare its students to deal with policy issues, the social sciences and liberal arts often do not prepare their students to deal with technological issues. In fact, the attraction of the social sciences and liberal arts disciplines for many students is the reason that they do not involve much mathematics and science. It is unrealistic to expect these students to become technology experts, but they do need to have an understanding of the complexity of many of the technical issues facing society and be comfortable in working with technologists in reaching solutions that are beneficial to society. Similarly, engineering students need to develop an understanding and appreciation of the policy sciences. A recent study by the National Academy of Engineering reinforces these concerns by stating that "this new level of intimacy necessitates that engineering (and engineers) develop a stronger sense of how technology and public policy interact."

To bridge this gap between engineering and public policy, we developed an introductory course for both political science and engineering students. Components of the course included an introduction to policy formulation, an examination of the institutions involved in public policy, the role ethics and values play in setting policy, and the examination of several specific policy topics. The course concluded with mock legislative oversight hearings. Surveys indicate that the class was well-received by the students and accomplished our goals.

\section{Engineering and A Flat World}

In his recent, best-selling book, The World is Flat, Thomas Friedman stresses that the world is becoming flat as a result of globalization and improved communication technologies. ${ }^{2}$ In the flat world, frictions have been reduced within the economy which allows new opportunities within the larger, global economy and new efficiencies can be realized in processed. However, these new opportunities, and the benefits they bring to a global economy, frequently come with local costs in terms of lost jobs and short-term losses in the local economy. Perhaps one of the most interesting examples Friedman relates is that of the American subsidiary of an Indian company successfully outbidding US firms to improve the processing of unemployment claims in Indiana. They were able to do this by using some local experts but bringing on most of their workforce from India for the short time they were required to complete the task. After the contract became a political issue, the governor stepped in, cancelled the contract, and required the job be broken into smaller pieces so that state and local firms could successfully bid on the project.

Friedman also notes that political science is likely to become a growth field in the coming years as result of the flattening world. As he says "we are going to see some very strange bedfellows making some very new politics. ${ }^{3}$ The change, it seems, is inevitable which leaves engineers with the choice of part of the force that drives this change or part of society that is affected by the change with no input. Given the tremendous impact that engineering has had on making the world flat, and the role that engineering is likely to play in the on-going flattening process, we believe that not only should engineers be part of the change process, but that political scientists should be better prepared to grasp the engineering and technical concepts responsible for this change. 
We are not alone in our belief. In their most recent report, the National Academy of Engineering's Committee on the Engineer of 2020 Phase II states that "[ $\mathrm{t}$ ] he steady integration of technology in our public infrastructures and lives will call for more involvement by engineers in the setting of public policy and in participation in the civic arena". They go on to claim that, in the years to come, engineering and public policy will increasingly converge necessitating that engineers have a better understanding of how engineering and public policy interrelate. ${ }^{5}$ Although there is no Committee on the Political Scientists of 2020, if there were, it is safe to assume that they would conclude political scientists need to better understand this interrelatedness as well.

\section{Genesis of the Course}

An article entitled School for Wonks ${ }^{5}$ spurred discussion of the role of public policy in engineering and prompted us to review the current state of education in the area. What we found was that most programs involving engineering and public policy were focused at the graduate level, but most of the problems in society were being handled by engineers without the benefit of that specialized graduate education. There were some exceptions, such as the course mentioned in the Prism article above, but that course only involved engineering students. Even the courses taught at the undergraduate level were focused mainly on engineering students and did not include political science, or other non-engineering students, in the classes. We wanted to have a truly interdisciplinary course, one which did not merely cross engineering department lines, but one which crossed college lines and thereby offered non-engineering and engineering students the opportunity to learn about engineering and public policy in the classroom.

Another problem we noted was that many problems in the engineering and public policy arena result from organizational behavior issues. Essentially, engineers and political scientists not only do not understand each other's professions; they do not understand each other. To effectively solve the problems facing society, the two disciplines not only have to learn to look at the problems from other perspectives; they have to develop an appreciation of other professions. A course, designed for both political science and engineering students, co-taught with one professor coming from political science and another coming from engineering, seemed to be the answer. Accordingly, we developed such a course and offered it for the first time, as an experimental course, in the Spring 2005 semester.

\section{Objectives of the Course}

We had several objectives of the course, but the primary objective was to bring together two seemingly different types of students and give them an opportunity to better understand each other while preparing them to tackle complex problems when they graduate. Achieving the larger goal necessitated that several sub-goals be developed and articulated to the students. When the course concluded, we wanted the students to be able to have a foundation in policy formulation that would allow them to analyze public issues with some academic rigor. We also wanted the students to have an understanding and appreciation of the impact that public policy can have on the practice of engineering.

Specific objectives for the course included introducing the students to policy science and how it could be used to explore public policy issues. Our desire for the course was that it be available to 
all undergraduate students and be kept open to even freshmen and sophomores. Therefore, we could assume no significant prior knowledge of policy formulation or even the institutions that set policy. We also wanted to introduce ethics into the course and examine the role that values play in solving problems. Through this we wanted to enhance the students' understanding of how ethical issues become involved in the practice of engineering and how ethics are related to public policy.

Given the course was being developed for undergraduates, we wanted to ensure the course did not become too theoretical and narrowly focused to the point that it was of interest to only a few. Our objective was to use specific examples to prepare the students to examine a broad range of issues upon completion of the course. Whether the students were interested in mechanical engineering or environmental policy, we wanted to prepare the students to be able to look at other engineering disciplines and policy areas in addition to their specific interests. Finally, we wanted to improve the communication skills of the students in the course. Not only would this help engineers better communicate to others the benefits engineering provides, something the Committee on the Engineer of 2020 also says is necessary, we, as instructors, could begin the conversation. To accomplish this objective we required numerous writing assignments, required oral presentations, and ensured that there was ample class discussion. For the second version of the course we added the requirement that each student read a national newspaper on a regular basis and, at some point of their choosing in the semester, provide a copy of an article they read related to engineering and public policy and their analysis of the article and the policy issue.

\section{Course Design}

Although the course was designed to meet the needs of both engineering and political science students, we were especially mindful of the Engineering 2000 criteria of the Accreditation Board for Engineering and Technology (ABET) and wanted this course to help meet those criteria. We believed that this course could be of particular value in meeting criterion 3. EC 2000 criterion 3 states:

\section{Engineering programs must demonstrate that their students attain:...}

(d) an ability to function on multi-disciplinary teams...

(f) an understanding of professional and ethical responsibility

(g) an ability to communicate effectively

(h) the broad education necessary to understand the impact of engineering

solutions in a global, economic, environmental, and societal context...

(j) a knowledge of contemporary issues... ${ }^{7}$

There were five principal sections to the course (see appendix), each focused on a specific portion of the policy process. It is tempting to begin courses such as this with an introduction to civics or American government. We opted to make the assumption that students enrolling in this course possessed a basic understanding of the operation of government and that is was not necessary to introduce topics such as how a bill becomes a law. The first section of the course began then with a discussion of different methods to look at complex issues before the public. These methods would form a foundation from which other parts of the course could be built. 
Using textbooks and other publications, students were provided with definitions of policy analysis and a framework from which policy analysis could be approached was covered.

The second portion of the course delved into the institutions involved in setting public policy which included the legislatures, bureaucracy, courts, interest groups, and the chief executive. This was done from a practical point of view and, again, assumed the students had at least a rudimentary knowledge of how government works. The obvious institutions such as the legislature were discussed, but even these discussions went beyond the typical civics lessons. Students were exposed to the importance of legislative staffs and the role that lobbyists play. The role of the bureaucracy was also covered. Rather than deride these institutions for their perceived lack of responsiveness, we explored the beneficial roles the institutions play and discussed how that perceived lack of responsiveness could also be viewed as a tempering influence which prevented rapid shifts in public policy.

Ethics and values were explored next by first forming a framework from which ethical dilemmas could be addressed. A process for making ethical decisions was discussed and the instructors stressed to the students that most ethical decisions are difficult because they are between two goods. The students were told that deciding between good and bad, right and wrong is easy; the difficulty with most ethical decisions is that the decision lies in the gray area where there is no obviously wrong choice. It was also in this section of the class that we explored how the values of society come into play and that problems are addressed by the different professions because of different values. An examination of how engineers make decisions and how political scientists make decisions was explored through class discussion. Students were able, through this dialog, to develop a better understanding of decision-making.

Given the course was developed for undergraduates we believed it was important to have concrete examples which reinforced the theoretical information covered earlier in the course. We also believed it would be valuable to have subject matter experts cover some public policy exemplars. To that end, we selected some pertinent public policy issues in engineering and chose to take two lecture periods to cover each topic. We agreed that we could cover telecommunications, nuclear energy, homeland security/homeland defense, and the environment. The first periods for each of these topics would be covered by a technologist who gave an overview of the scientific and engineering principles involved. The second day a policy expert was brought in to discuss the issues involved in setting the policy. Due to scheduling difficulties and the availability of speakers, some of the experts were academicians, but several were current or former practitioners.

To conclude the class, the instructors held four mock Senate hearings. In these hearings, we played the role of Senators. Students were divided into four groups which were specifically developed to include both engineering and political science students on each team. They were then assigned to one of four cases and further assigned to represent a specific party involved in the case. The four cases we used for this portion of the course were the mine blast in Centralia \#5, the crash of ValueJet Flight 592, the Space Shuttle Challenger explosion, and how the city of Wichita handled contamination caused by a local industry. 
Each team was provided with copies of the cases and given several weeks to develop their testimony. Over four class periods, hearings were held. A classroom was set up to resemble a Senate hearing room complete with witness tables, a gallery for the students who were not testifying on that day, and a gavel. Each side was given a specific period of time to present their testimony and each team member was expected to actively participate. Following the presentation of the testimony, the "Senators" posed questions to each side in a realistic manner. The questions were designed to both elicit additional information and to make the students think on their feet. At the conclusion of each class, the record was held open for one week to allow the students to revise and extend their remarks which were then submitted for grading. The "Senators" also reviewed the points discussed during the hearing with the class, and pointed out some options available to the policy-makers that may not have been explored.

\section{Course Grading}

Grading for the class was essentially based on class participation, the legislative oversight hearing simulation (both written and oral testimony), a final exam consisting of an in-class case analysis, and in-class response papers. Class participation was heavily weighted (something the engineering students were not accustomed to) in order to ensure the different majors communicated with each other. Throughout the course, we would often let students answer other students' questions before we either corrected or amplified on the responses.

To encourage active learning, we also required six in-class response papers. At the end of topical areas, we gave the students a question that had to be answered in class and could not exceed two hand-written pages. This meant the students had to keep up with the course material and had to assimilate the material quickly in order to answer the question. It was also our goal of having this requirement to get the students to practice organizing their thoughts and written responses.

Papers were graded based on criteria delineated in the syllabus but a formal rubric for each paper was not used. For A level work we expected the students to demonstrate an extensive grasp of the relevant basic facts which was well-communicated, developed, and showed the students had a full understanding of the topic and could show relationships between facts and concepts. To earn a B a student had to demonstrate a substantial grasp of the facts and clearly express their understanding. If a student grasped many of the relevant facts and showed a general understanding of the facts they were given a C. To earn a D a student would only grasp some of the facts and demonstrate a partial understanding of the concepts and relationships. If a student only grasped a few of the concepts and demonstrated little understanding of the facts, they were given a grade of $F$. There was a great deal of subjectivity in the grading and feedback was provided to help the students present stronger arguments. The political science students were accustomed this type of grading but the engineering students took a little while to adjust to grades that were numerical. The assignments did however help the students get experience in dealing with questions that did not always have a right and wrong answer.

\section{Results}

The feedback received from the students in the class was overwhelmingly positive and encouraging. The students thought they had learned from the class and we believed we had 
accomplished our objectives. Although no single class can make someone a policy expert, this course did appear to raise the awareness of our future policy makers.

At the conclusion of the course, we administered a survey to the students to determine if our objectives had been met and to solicit input on what they liked and what they disliked about the course. Two separate but similar surveys were used; one was given to the political science students and a slightly different survey was given to the engineering students. The differences between the surveys were that we asked the engineering students what they thought about the political science students and their profession, and we asked the political science students what they thought about engineers and engineering. With only 10 engineering students and 16 political science students enrolled, we are not prepared to make broad generalizations but we have begun the process of collecting data for each class. Over the years we will gather enough data that should allow us to draw conclusions on the differences between engineering and political science students and how they approach problems.

Because one of our objectives was to improve the writing ability of the students, we asked if they thought the amount of writing in the class was about right. As shown in figure 1, most of the students thought the amount of writing was about right. This was particularly interesting because we, the ones who had to grade the writing, thought there was too much writing. The six in-class writing assignments imposed a heavy grading load because the students were given detailed feedback on the assignments. Grading could have been easier had it not been done with such detail. We did allow one assignment to be completed at home and received mixed reviews on that assignment: some liked it, others did not. Doing the writing at home did relieve some of the pressure from the assignment but the students also spent more time on the writing. We have decided that, in spite of the survey results, the number of writing assignments will be reduced in the future, but they will still be graded in detail so that the students can improve their writing.

The amount of writing in this class was about right.

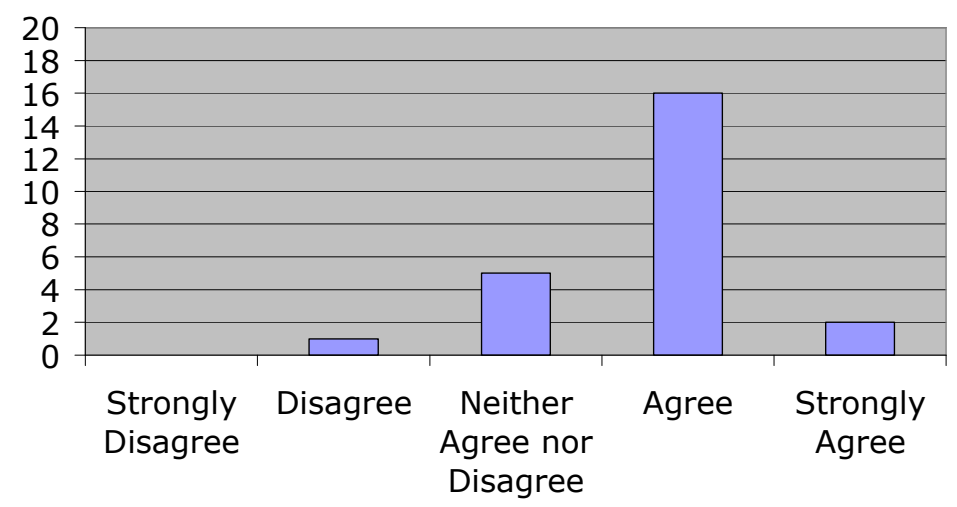

Figure 1.

As shown in figure 2, the students also appreciated the way in which the class was divided into specific topics. This not only allowed them to focus on specific areas, it allowed us to divide the teaching tasks and responsibilities by topic. One of the more difficult parts of conducting a class 
in this fashion was the section in which we examined specific policy topics. Scheduling outside experts to come to campus proved to be somewhat more difficult than initially expected. The experts, being busy people, would have last minute scheduling issues arise, but they all worked with us well. When they could not make a class, they sent a colleague to take their place. We had remarkable responses when we contacted the policy experts and they often stated how valuable a course such as this would be. One governmental agency head, who hires many engineers, said this could be the most valuable classes one of his engineers could take.

The way the class was divided into topics was useful.

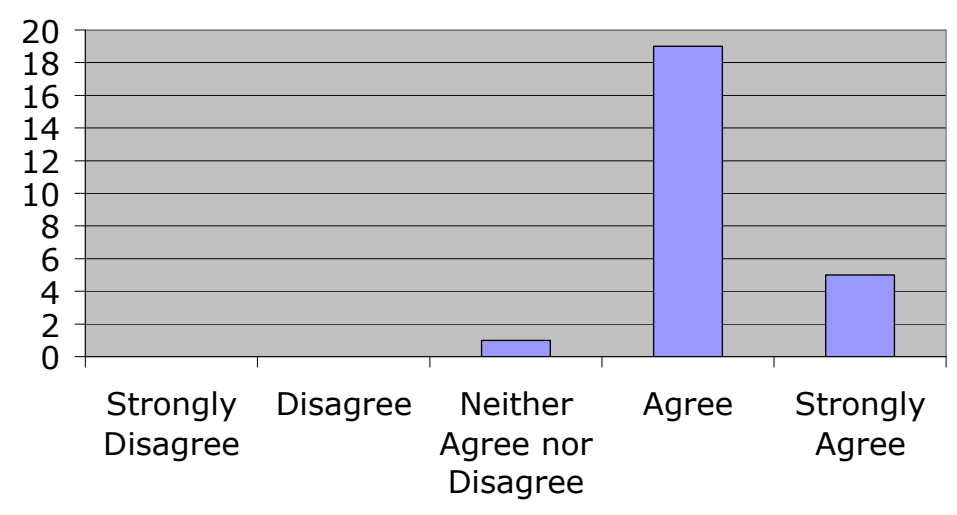

Figure 2.

One concern we had with the grading was whether or not each team member would carry their full weight on the legislative oversight hearing assignment. It was obvious that some teams shared the load equally; others shared the load, but not equally; and one team had all but one member quit attending classes leaving him to testify alone. We explained to the students that, in their professional careers, they will often run across those who do not share the load equally but the job must still be done and, if done poorly, reflects on everyone on the team. We considered the possibility of using peer reviews of the teams when we assigned grades but so far have opted to give the same grade to each team member. Figure 3 shows that, in spite of the few problems, most of the students thought everyone contributed. 


\section{Everyone in my group contributed to the}

case study presentation.

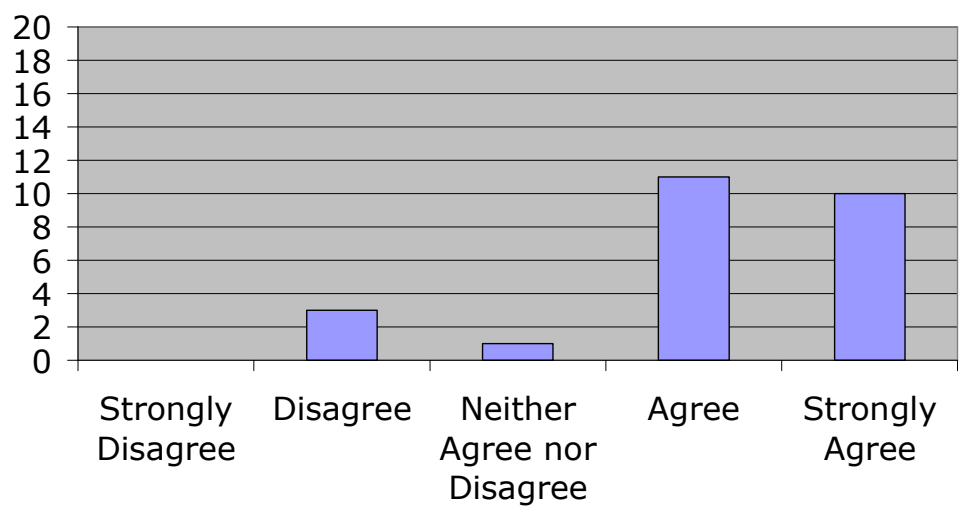

Figure 3.

Through this class, students developed a better understanding of public policy issues. This is shown by the data in Figure 4 as well as their performance in class. It was not uncommon to hear engineering majors asking questions you would expect to hear from a political science major, nor was it uncommon to hear political science students answering questions in a way an engineering major might ask them. Our students were examining issues from different points of view than they would normally.

I have a better understanding of public policy issues as a result of taking this class.

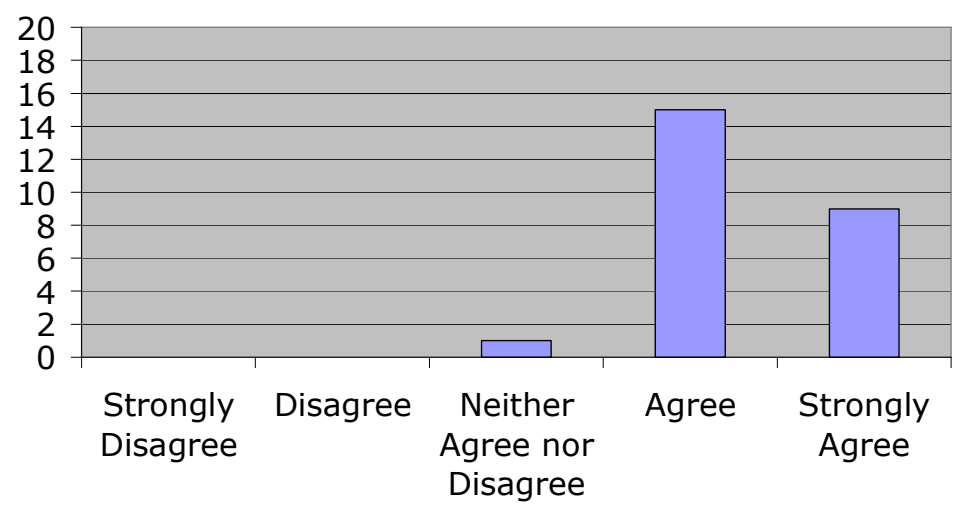

Figure 4.

One of the major objectives of the class was to enable political scientists and engineers to gain a better understanding and appreciation of the other's profession. By improving perceptions and encouraging dialog, we hope to produce students who are better prepared to tackle the tough public policy issues we will face in the coming years. Results from the survey indicate that we achieved this objective but the data are somewhat confusing. As can be seen in figures 5 and 6 , we asked essentially the same question in two different ways, and got slightly different results. 
One goal for future classes will be to move more students into the "agree" and "strongly agree" categories.

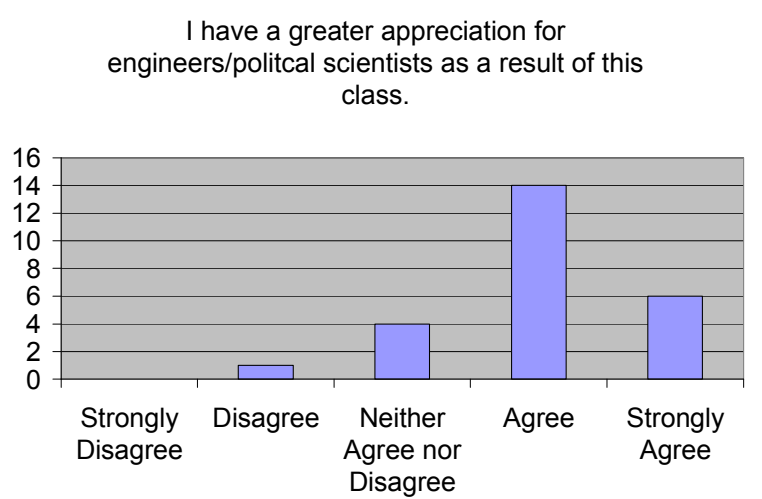

Figure 5.
My appreciation of engineers/political scientists improved as a result of this class.

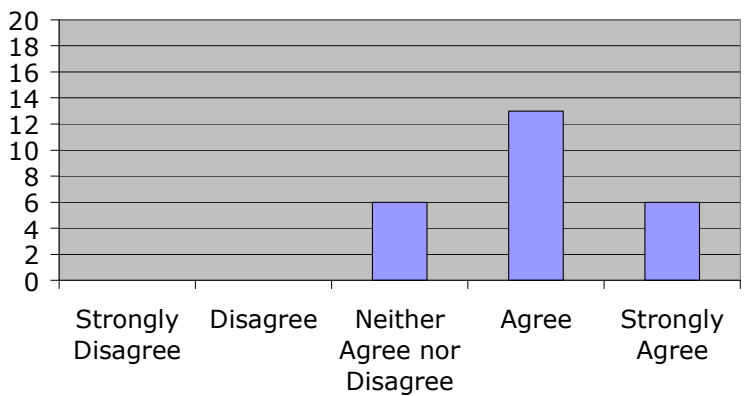

Figure 6.

Perhaps the best indicator of the success of the course is the fact that $76 \%$ of those in the class are likely to mention this course in a job interview, apparently thinking it will give them an edge over other candidates. Fully $92 \%$ of the students said they would recommend the course to a friend.

The majority of students in the class also stated that they were likely to mention this class in a job interview as shown in Figure 7.

\section{I will likely mention this course}

in a job interview.

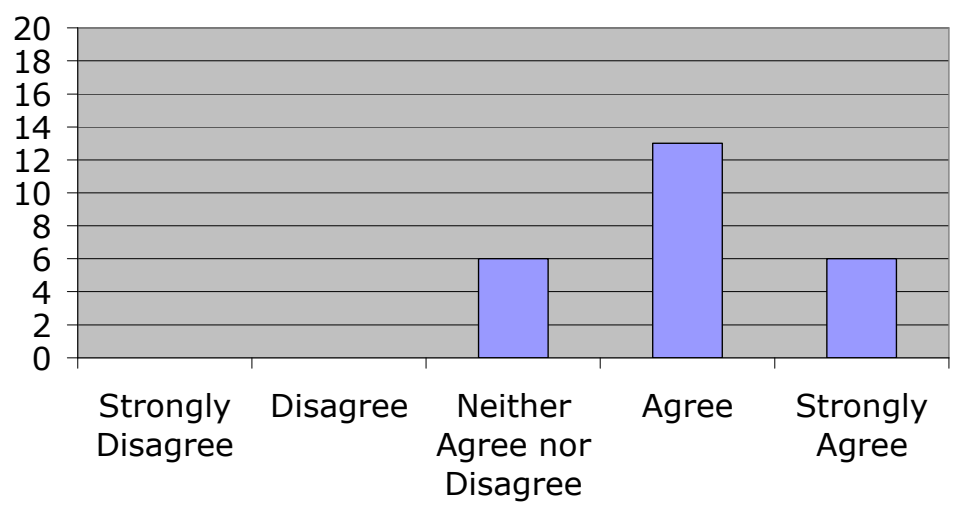

Figure 7.

The majority of the students, as shown in Figure 8, believe that this course will give them an edge over their colleagues who did not take the class. 
I believe this class will give me an edge over my colleagues who do not take it.

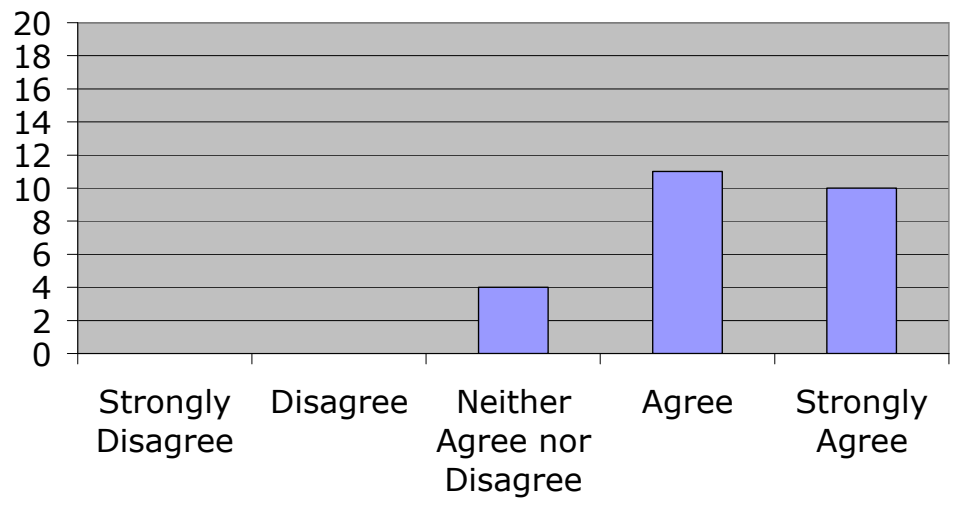

Figure 8.

Although the day may well come that such a class is a requirement for a job, today we are pleased that it can be used to set aside our students from others. As the world continues to become flatter, our students are prepared to take a leadership role in the flattening process.

Future Plans

This class was offered as an experimental course and has now been approved by our University Committee on Course and Curricula as a regular course. We plan to offer it once a year for all interested students and hope that eventually it will be attractive to other majors, especially those in science fields and majors that are likely to produce future lawyers. The content of the course will remain the same but we will make slight adjustments in the specific policy topics covered and the cases given to the students for the legislative oversight hearing simulations.

We also believe there is need for more courses and programs of this type at the undergraduate level. Not only would such additional courses increase the interest in engineering and public policy at the graduate level, it would produce undergraduates better capable of dealing with the difficult public policy issues. We have discussed plans to offer a more advanced follow-on course which would be taught at the junior or senior level and explore technology and public policy at a deeper level. We would also like to offer a seminar course at the senior level. These courses would remain interdisciplinary and further enhance communication skills.

Perhaps the greatest task we face is getting this course more widely accepted by the various engineering disciplines. The Department of Political Science and Public Policy has openly accepted the course and allows their students to use it to satisfy their public policy course requirement. Engineering departments have acknowledged the value of the course but are finding it difficult to work it into their already full curricula. Some departments are open to allowing the course to count as a technical elective, but others admit they have little room to spare. Some engineering students will take the class regardless of whether it applies to meeting their degree requirements or not, but many others would benefit from the class if we could get them degree credit. One option we are currently discussing is getting the course classified as one which meets 
the University Core Curriculum. If this happens, then more students will be able to take the course and count it toward degree requirements. However, this will come at the expense of another social science course. As pressure from state oversight boards to reduce the number of hours to obtain a college degree increases across the nation and the amount of material needed to be comprehended by engineering students increases, the idea that the baccalaureate degree be considered a pre-engineering degree with a master's degree being required to be a "master engineer" becomes more salient.

\section{Conclusion}

Recognizing the need to bridge the gap between the engineers who develop the technology and the political scientists who set the policy regulating the technology, we developed a course which brought the two disciplines together. We gave the students a foundation in public policy and helped them apply policy science to complex technical issues preparing them for careers in a flat world. As a result, we have engineering and political science students who better understand the pertinent issues in public policy and have laid a foundation for them to continue their dialog. We have also developed the foundational course for an even greater, more in-depth program in engineering and public policy.

\section{Acknowledgements}

This paper, in an earlier version was presented at the 2006 ASEE Southeastern Section Annual Conference in Tuscaloosa, Alabama, April 2-4, 2006.

\section{References}

1. National Academy of Engineering, The Engineer of 2020, Visions of Engineering in the New Century, National Academies Press, Washington, DC, 2004, pg. 37.

2. Friedman, Thomas L. The World is Flat: A Brief History of the Twenty-First Century, Farrar, Straus, and Giroux, New York, NY, 2005.

3. Friedman, p. 201.

4. National Academy of Engineering, Educating the Engineer of 2020, Adapting Engineering Education to the New Century, National Academies Press, Washington, DC, 2005.

5. National Academy of Engineering (2005), p. 11.

6. Creighton, Linda, "School for Wonks", ASEE Prism. American Society for Engineering Education, Washington, DC, February 2004.

7. ABET, "2006-2007 Criteria for Accrediting Engineering Programs”, ABET, Baltimore, MD, 2005 , pg 4. 


\section{Appendix}

Course Schedule and Topics Covered

\begin{tabular}{|c|c|}
\hline NUMBER OF CLASSES & $\underline{\text { TOPIC }}$ \\
\hline 1 & COURSE INTRODUCTION \\
\hline \multirow[t]{4}{*}{3} & THE ACTIVITIES OF POLICY ANALYSIS \\
\hline & Defining Policy Analysis \\
\hline & Policy Analysis Frameworks \\
\hline & Future of Engineering \\
\hline \multirow[t]{6}{*}{9} & INSTITUTIONS IN PUBLIC POLICY \\
\hline & Legislatures \\
\hline & Bureaucracy \\
\hline & Courts \\
\hline & Interest Groups \\
\hline & Chief Executive Leadership \\
\hline \multirow[t]{2}{*}{3} & ROLES OF VALUES AND ETHICS \\
\hline & Frameworks \& Applications \\
\hline \multirow[t]{5}{*}{8} & SPECIFIC POLICY TOPICS \\
\hline & Telecommunications \\
\hline & Nuclear Power \\
\hline & Environment \\
\hline & Homeland Security/Defense \\
\hline 4 & $\begin{array}{l}\text { LEGISLATIVE OVERSIGHT HEARINGS } \\
\text { SIMULATION }\end{array}$ \\
\hline 1 & COURSE REVIEW \& WRAP-UP \\
\hline 1 & FINAL EXAM \\
\hline
\end{tabular}

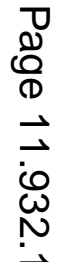

